\title{
THE MORPHOLOGY OF CATARACT AND VISUAL PERFORMANCE
}

\author{
NICHOLAS A. PHELPS BROWN \\ Oxford
}

\begin{abstract}
SUMMARY
The various effects of cataract on vision are reviewed. The morphological types of senile cataract are classified into three basic categories: cortical spoke, nuclear and posterior subcapsular (PSC). The significant basic effect of cataract on the optical system of the eye is that of light scattering. Forward light scattering (light scattered towards the retina) accounts for reduced contrast sensitivity, for glare and for reduced visual acuity. Other effects of cataract are a myopic shift, a possible astigmatism change, monocular diplopia and polyopia, colour vision shift, reduced light transmission, and field of vision reduction. The effect of the various cataract morphologies on these functions is discussed. The nature of the effect varies with the degree of the cataract and with the cataract morphology. The assessment of a patient's visual disability is therefore not a simple task and cannot be based solely on the visual acuity nor on the objective measurement of the cataract.
\end{abstract}

Many of the various separate effects of cataract on vision have been studied and reported in the literature. This paper attempts to review all the known effects.

The morphological types of senile cataract fall largely into three basic categories: ${ }^{1}$ Cortical spoke (or cuneiform) (Fig. 1), nuclear (Figs. 2 and 3) and posterior subcapsular cataract (PSC) (Fig. 4). Cataracts have been classified into these three categories for the purpose of clinical studies.

These cataract types can be graded clinically ${ }^{2-5}$ and can be measured photographically. ${ }^{6-8}$ Within each group there is variation in the morphology and nuclear cataract is clearly not a single entity. It comprises both white scattering and brunescence (Figs. 2 and 3), which although they commonly occur together appear to be separate entities. Each of these nuclear features can be graded, ${ }^{9}$ but it is only the degree of scattering which has so far been measurable.

The systems of classification and measurement are essential to ordered research work, but are necessarily an

Correspondence to: N. A. Phelps Brown, Clinical Cataract Research Unit, Nuffield Laboratory of Ophthalmology, Walton Street, Oxford OX2 6AW, UK. oversimplification and tend to ignore the additional features associated with cataract including water clefts, ${ }^{10}$ vacuoles, fibre folds ${ }^{11}$ and retrodot opacities. ${ }^{12,13}$ These are taken into account in the Oxford Clinical Cataract Classification and Grading System, ${ }^{3.5}$ but presently lack systems for measurement. Clinical experience suggests that these features affect vision, but the extent of the effect cannot be estimated until these features can be measured.

The most significant basic effect of cataract on the optical system of the eye, common to all types of cataract, is that of light scattering, so that the image received by the retina is desaturated by the contrast-reducing effect of the scattered light. The degree of this effect depends on the proportion of the pupillary area that is occupied by the cataract and upon the morphology of the cataract. Once the pupil is fully occupied by opacity, the retina receives only scattered light and no formed image. Forward light scattering (light scattered towards the retina) accounts for reduced contrast sensitivity, for glare and for reduced visual acuity. Objective methods of cataract assessment can measure only the percentage of the pupil area occupied by cataract and backward scatter (light scattered away from the eye), rather than the forward scatter that affects the retina. It is reasonable to suppose that there is a relationship between forward scatter and back scatter, but this has not been fully quantified. ${ }^{14}$

Light scattering in the lens is not unique to cataract and occurs in the normal ageing lens leading to increasing glare after the age of $50 .{ }^{15}$ This is likely to be the compounded result of the increase in lens thickness (causing the light to traverse more fibre protoplasm plus a greater number of fibre membranes) together with the increase in lens protein molecular size with age. ${ }^{16}$

There are several demonstrable subjective ways in which vision is affected by cataract: (1) myopic shift, (2) astigmatism, (3) monocular diplopia, (4) contrast sensitivity reduction, (5) glare, (6) colour shift, (7) reduced light transmission, (8) field loss and (9) visual acuity reduction. Visual acuity is considered last because it has a relatively low level of importance to the patient, in spite of being the most commonly used assessment. 


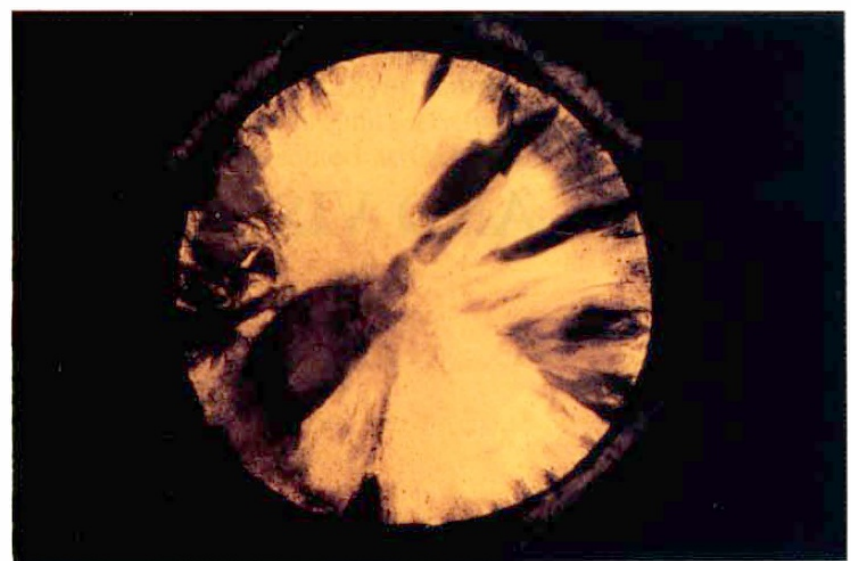

Fig. 1. Cortical spoke cataract (retro-illumination).

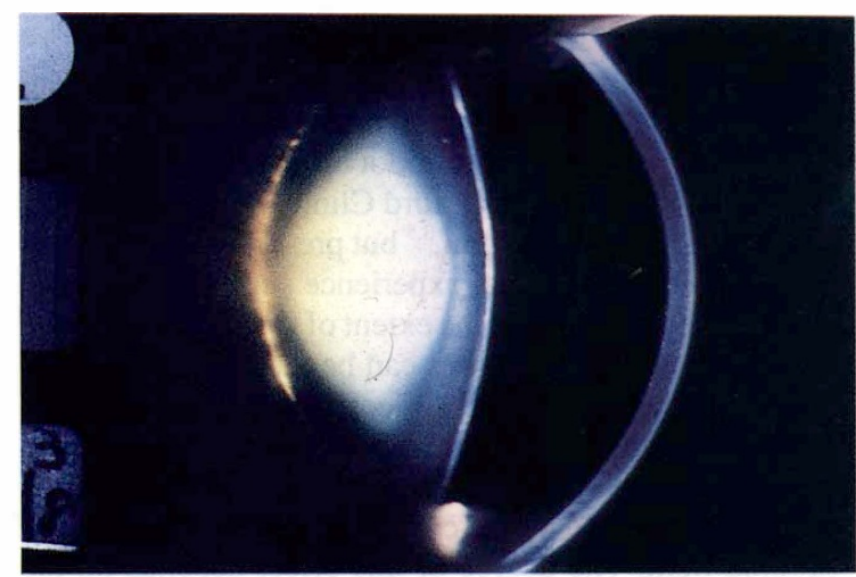

Fig. 2(a)

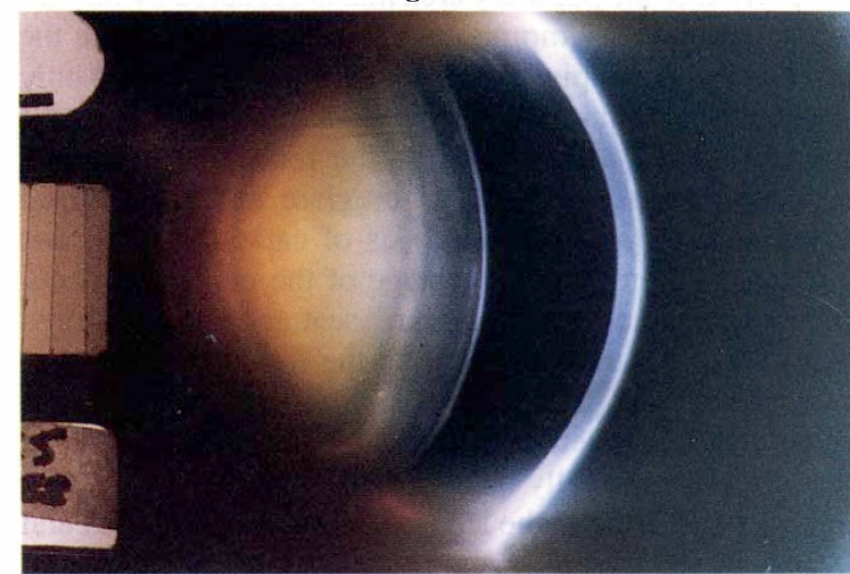

Fig. 2(b)

Fig. 2. (a) White scattering nuclear cataract (slit image). (b) Brunescent nuclear cataract (slit image).

\section{EFFECTS OF CATARACT ON VISION}

\section{Myopic shift}

The normal ageing human lens produces a gradual hypermetropic shift, ${ }^{17}$ which is offset by the development of nuclear cataract if this occurs. ${ }^{18}$

Ageing patients not developing cataract, and those developing cortical or subcapsular cataract without nuclear change show the continued hypermetropic shift, as does the healthy ageing eye. It is possible to predict that an ageing person is developing nuclear cataract if he or she

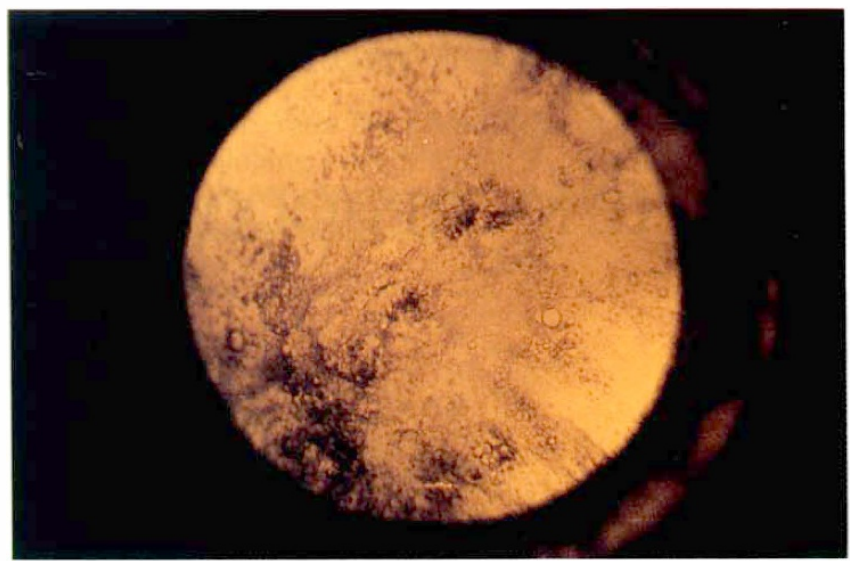

Fig. 3. Posterior subcapsular cataract (retro-illumination).

shows 0.5 dioptre or more myopic shift between refractions 2 years apart. ${ }^{18}$ It is considered that the degree of scatter in the lens is related to the refractive index, ${ }^{19}$ which would account for the increasing lens strength in nuclear cataract.

\section{Astigmatism-}

This aspect of cataract vision appears not to have been researched. There is clinical experience that astigmatic shifts may occur. Astigmatism is understandable in terms of an uneven change in refractive index in the lens and is seen in conjunction with cortical spoke cataract.

\section{Monocular Diplopia}

Monocular diplopia is common in cataract, particularly with cortical spoke cataract and in conjunction with water clefts. The patient may experience multiple images (polyopia). Water clefts ${ }^{10}$ form typical radial wedge shapes and appear to contain a fluid of lower refractive index than the surrounding lens. The wedge-shaped nature of their crosssection represents a prism.

It takes only a small prismatic effect due to refractive index changes to produce the double image. The illustration of monocular diplopia (Fig. 4) was made with a prism of only 1 dioptre covering part of the lens.

\section{Contrast Sensitivity Reduction}

Contrast sensitivity testing is a research field in which the findings relate directly to the real world of the cataract patient. $^{20,21}$ All cataracts lower contrast sensitivity and the posterior subcapsular cataract has been shown ${ }^{22}$ to be the most destructive of contrast sensitivity. The performance of the eye with cataract is reduced throughout the spatial frequency range. High spatial frequency contrast sensitivity results in cataract correlate to Snellen visual acuity testing, and so in cataract clinical trials it is the low spatial frequency contrast sensitivity (1-2 c/degree) measurements that are the most informative. The patient has difficulty in distinguishing relatively large objects (low spatial frequency) of low contrast difference from their surroundings, although high spatial frequency objects of high contrast may be quite well seen ${ }^{23}$ (Fig. 5). The effect is evident 


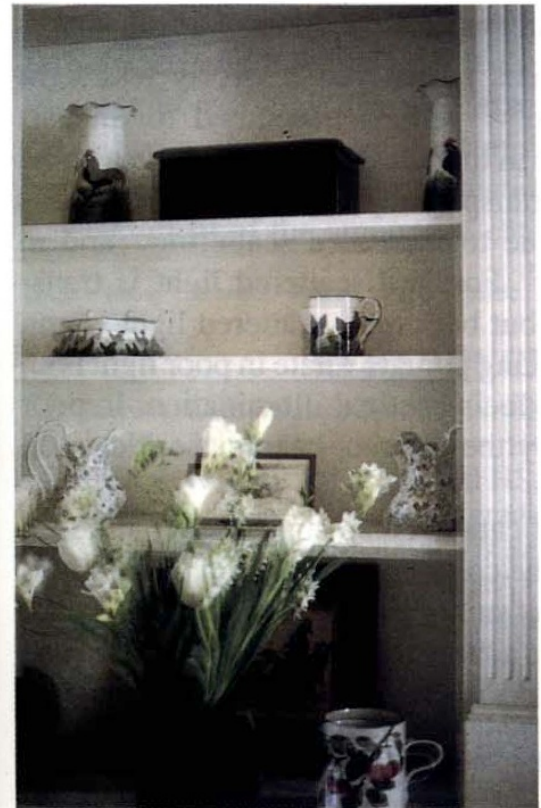

Fig. 4. Monocular diplopia produced by a prismatic effect of 1 prism dioptre.

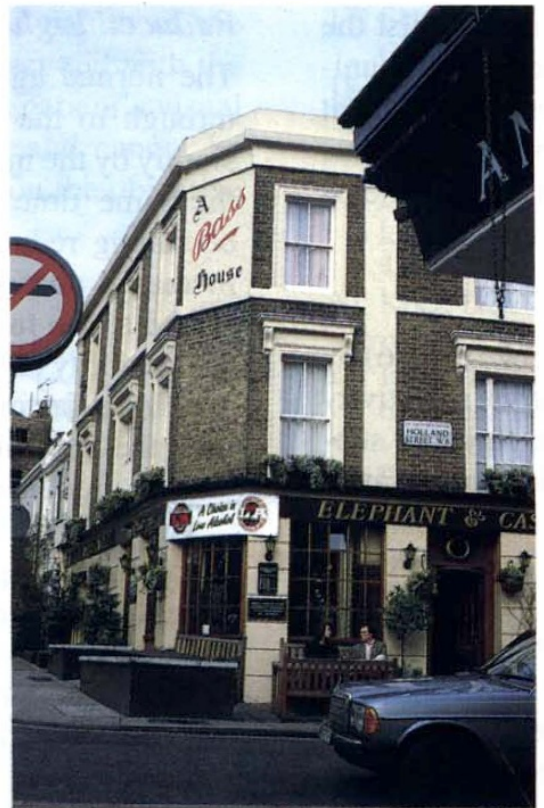

Fig. 5a

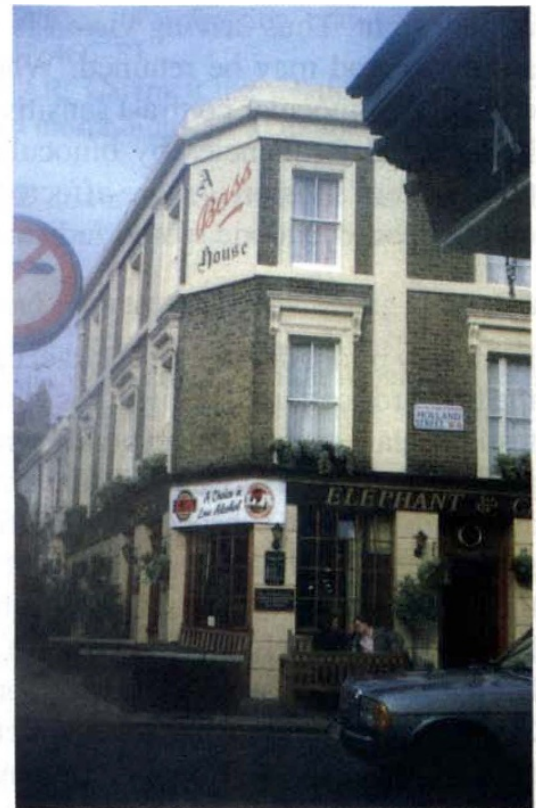

Fig. 5b

Fig. 5. (a) Normal view. (b) View through a simulated grade 3 (Oxford grading) cortical cataract. The high-contrast letters can be read, but the low-contrast seated subjects are not discerned.

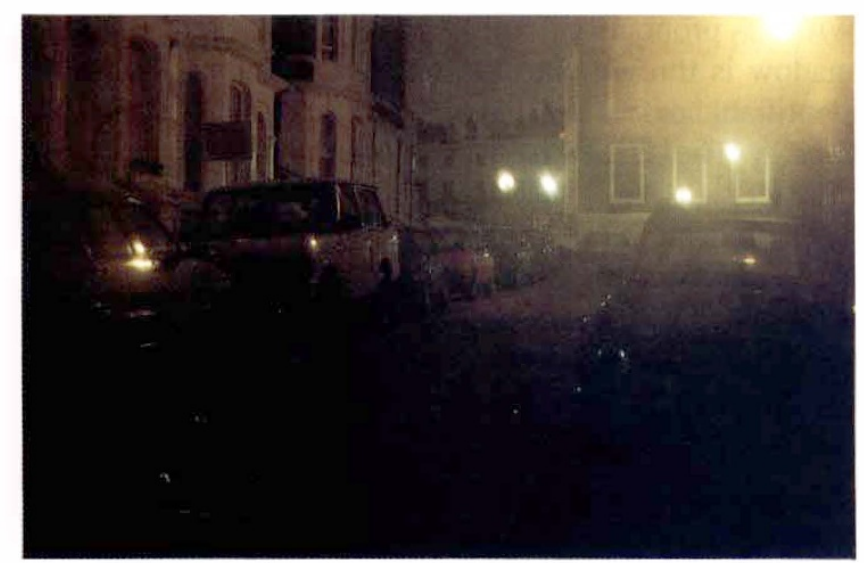

Fig. 6a

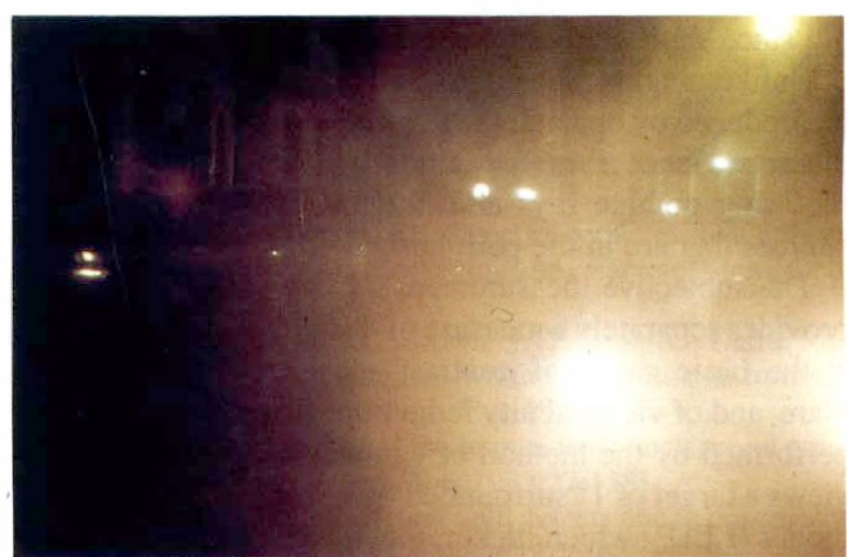

Fig. 6b

Fig. 6. (a) Cortical cataract (Oxford grade 3) vision at night without glare source. (b) With the glare source from headlights.

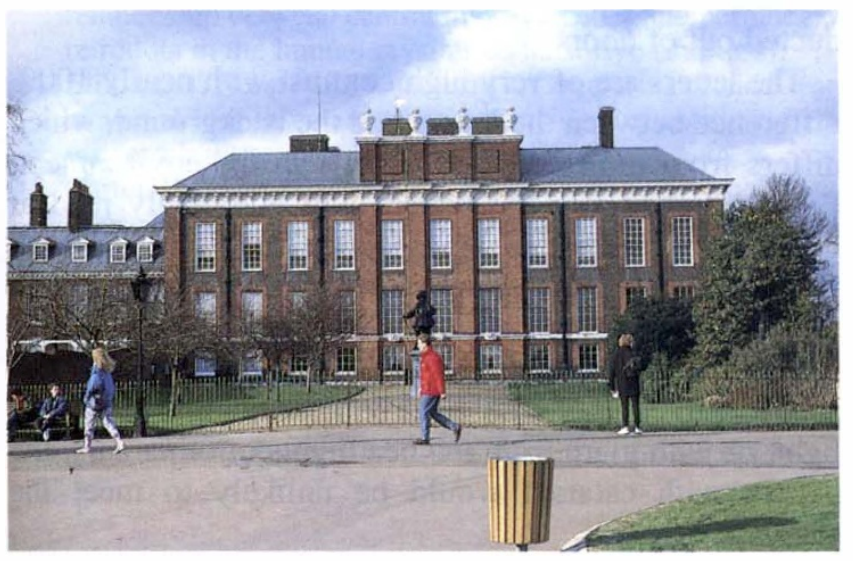

Fig. 7a

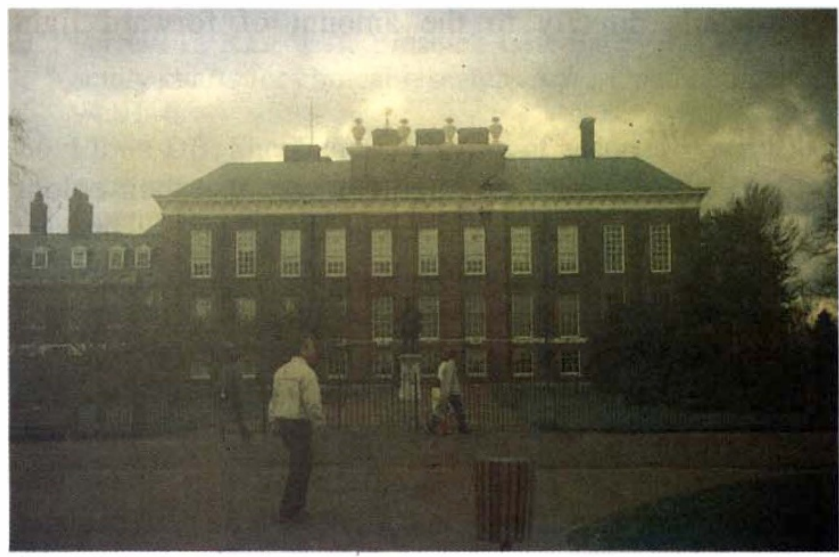

Fig. $7 b$

Fig. 7. (a) Normal view. (b) View through a simulated grade 3 brunescent cataract. 
in poor light. Thus driving vision is impaired, whilst the ability to read may be retained. When a cataract is uniocular, the binocular contrast sensitivity test is affected at high spatial frequencies by binocular inhibition. ${ }^{24}$ Thus these patient's vision is more affected than measurements on the good eye alone would indicate.

\section{Glare}

Even very minor degrees of cataract cause glare (Fig. 6) by the forward scattering of light. As with contrast sensitivity testing, glare testing corresponds with the patient's subjective impression of visual difficulty. ${ }^{20}$ All forms of cataract cause glare, especially cortical and posterior subcapsular. Glare affects the patient most severely when the light source is close to the object being looked at. This happens particularly in the context of night driving. Glare has a relatively weak effect at high contrast, such as with a Snellen chart, and is most accurately measured with a standardised glare source surrounding a contrast sensitivity test display. ${ }^{23,25}$

Both contrast sensitivity and glare have been shown to correlate with the degree of the cataract as measured by cataract grading ${ }^{22}$ using the Oxford Grading System.,

Glare is greater at short wavelengths and is reduced by a $550 \mathrm{~nm}$ cut-off yellow filter. ${ }^{26}$ This is an anticipated finding since short wavelengths are more readily scattered.

Unlike contrast sensitivity reduction, some glare may be produced by opacities which do not lie within the pupil diameter, since these opacities will scatter light when receiving oblique rays and thus cause glare from light sources that are in the peripheral field.

The subjective measurement of forward light scatter ${ }^{14}$ provides separately a measure of this effect of cataract that is the basic cause of contrast sensitivity reduction, of glare, and of visual acuity reduction. This measurement is performed by the method of van den Berg. ${ }^{27}$ The patient views a target of $1^{\circ}$ surrounded by a ring of light-emitting diodes (LEDs) which flicker, the flicker being seen by the patient as superimposed on the target because of forward light scatter. The target is made to flicker in counterphase to the LEDs until flicker is indistinguishable. The amplitude of the luminance to produce zero perceived flicker corresponds directly to the amount of forward light scatter.

\section{Colour Shift}

Patients with cataract are often unaware that their colour vision is defective until it is restored to them by cataract surgery. The novel brightness of the colours seen through the lens implant is often more impressive to the patient than the improvement in acuity.

The healthy ageing lens becomes progressively more absorbent at the blue end of the spectrum ${ }^{28,29}$ and this effect is exaggerated in cataract and particularly in nuclear brunescent cataract. Thus the patient with nuclear cataract is affected by reduced colour sense (Fig. 7) as well as by reduced contrast sensitivity, glare, and by the myopic shift.

\section{Reduced Light Transmission}

The normal ageing lens passes progressively less light through to the retina. ${ }^{28,29}$ This is accounted for in part simply by the increase in thickness of the lens with age. At the same time the transparency of the ageing lens is becoming reduced, due to increased scattering ${ }^{30}$ and to increased absorption. ${ }^{31}$ Forward scattered light is transmitted to the fundus, but backward scattered light is not. The inability of the ageing pupil to dilate in poor light is an additional factor in reducing retinal illumination. In poor light the absorption by the cataract becomes critical and vision is reduced.

The other effects of cataract also contribute to reduced vision in poor light. The contrast of objects in poor light is lower than it is in direct sunlight, so that the patient's poor contrast sensitivity has a larger effect. Glare sources, such as headlights, are likely to be present in conditions of otherwise poor illumination.

Occasionally patients with cataract report improved vision in poor light. This occurs when there is a smalldiameter cataract placed centrally on the optic axis, so that vision improves with pupil dilatation.

\section{Field Loss}

Cataract can affect the visual field in one of two ways. With a pronounced spoke cataract a wedge-shaped shadow is thrown onto the retina and this can cause an identifiable defect in the peripheral field on field of vision testing. The effect is most noticeable with posterior cataract. ${ }^{32}$

The reduction in light transmission can cause an established glaucomatous field defect to appear to be increasing when tested with quantitative perimetry ${ }^{33,34}$ An increase in the illumination of the test stimulus will reverse this effect, but the clinician is left with uncertainty as to what is really happening at the retinal level.

\section{Visual Acuity Reduction}

Visual acuity testing is conducted under ideal circumstances, which are not normally met in the real world. The room is softly lit and all sources of glare are removed. For research studies, the logarithmic letter charts ${ }^{35,36}$ are to be preferred. Visual acuities are reduced if the test is conducted out of doors. ${ }^{37}$

The letters are of very high contrast with nearly $100 \%$ difference between the letters and the background, which differs from most common objects in the environment. Even the print that the patient will commonly read at home, such as that in newspapers, does not approach $100 \%$ contrast. Thus visual acuity measurement tends to overestimate the patient's visual ability. ${ }^{38}$

It is common to regard a visual acuity of $6 / 12$ as just adequate to comply with the driving standard, but in poor light, or with glare from the headlights of other cars, the patient with cataract would be unlikely to meet the standard.

\section{CONCLUSION}

Cataract affects vision in many more ways than visual 
acuity testing alone would indicate. The nature of the effect varies with the degree of the cataract and with the cataract morphology. The assessment of a patient's visual disability is therefore not a simple task and cannot be based solely on visual acuity testing nor on the objective measurement of the amount of cataract.

Key words: Cataract, Visual performance.

\section{REFERENCES}

1. Brown NAP. Atlas of ophthalmology, vol 11, The lens (Spalton D, editor). London: Gower, 1983.

2. West S, Rosenthal F, Newland HS, Taylor HR. A comparison of methods for typing and grading lens opacities for field surveys. Invest Ophthalmol Vis Sci 1985;26 (Suppl):119.

3. Sparrow JM, Bron AJ, Brown NAP, Ayliffe W, Hill AR. The Oxford clinical cataract classification and grading system. Int Ophthalmol 1986;9:207-25.

4. Leske MC, Chylack LT, Khu P, Sperduto R, McKarthy D, Wu SY. Evaluation of a simple classification system based on standard photographs. Invest Ophthalmol Vis Sci 1987; 28 (Suppl):323.

5. Sparrow JM, Ayliffe W, Bron AJ, Brown NAP, Hill AR. Inter-observer and intra-observer variability of the Oxford clinical cataract classification and grading system. Int Ophthalmol 1988;11:151-7.

6. Brown NAP, Bron AJ, Sparrow JM. Methods for evaluation of lens changes. Int Ophthalmol 1988;12:229-35.

7. Sparrow JM, Brown NAP, Shun-Shin GA, Bron AJ. The Oxford modular cataract image analysis system. Eye 1990; 4:638-48.

8. Harris ML, Smith GTH, Brown NAP. Inter- and intra-observer reproducibility of the new Oxford CCD Scheimpflug camera. Eye 1991;5:487-90.

9. Sparrow JM, Hill AR, Ayliffe W, Bron AJ, Brown NAP. Human lens nuclear colour matching and brunescence grading in vivo. Int Ophthalmol 1988;11:139-49.

10. Shun-Shin GA, Vrensen G, Brown NP, Willekens B, Bron $\mathrm{AJ}, \mathrm{McDonald} \mathrm{B}$. Does the pathogenesis of water clefts reside in the lens fibre membrane? In: Vrensen G, Clauwaert J, editors. Topics in aging research in Europe: Eye lens membranes and aging. EURAGE 1992;15:261-71.

11. Brown NAP, Vrensen G, Shun-Shin GA, Willekens B. Lamellar separation in the lens: the case for fibre folds. Eye 1989;3:597-605.

12. Bron AJ, Brown NAP. Perinuclear lens retrodots: a role for ascorbate in cataractogenesis. $\mathrm{Br} \mathrm{J}$ Ophthalmol 1987;71: 86-95.

13. Shun-Shin GA, Bron AJ, Brown NAP, Sparrow JM. The relationship between central nuclear scatter and perinuclear retrodots in the human crystalline lens. Eye (in press).

14. Elliott DB, Hurst MA, Weatherill J. Comparing clinical tests of visual loss in cataract patients using a quantification of forward light scatter. Eye 1991;5:601-6.

15. Carter JH. The effect of aging upon selected visual functions. In: Sekuler R, Kline D, Dismukes K, editors. Aging and human visual function. New York: Alan R Liss, 1982: 121-30.

16. Spector A. Aging of the lens and cataract formation. In: Sekuler R, Kline D, Dismukes K, editors. Aging and human visual function. New York: Alan R Liss, 1982:27-43.
17. Slataper FJ. Age norms of refraction and vision. Arch Ophthalmol 1950;43:466-81.

18. Brown NAP, Hill AR. Cataract: the relationship between myopia and cataract morphology. Br J Ophthalmol 1987;71: 405-14.

19. Huggert A. Are the discontinuity zones of the crystalline lens iso-indicial surfaces? Acta Ophthalmol 1946;24: 417-21.

20. Koch DD. Glare and contrast sensitivity testing in cataract patients. J Cataract Refract Surg 1989;15:158-64.

21. Elliott DB, Hurst MA, Weatherill J. Comparing clinical tests of visual function in cataract with the patient's perceived visual disability. Eye 1990;4:712-17.

22. Elliott DB, Gilchrist J, Whitaker D. Contrast sensitivity and glare sensitivity changes with three types of cataract morphology: are these techniques necessary in clinical evaluation of cataract? Ophthalmic Physiol Opt 1989;9:25-30.

23. Elliott DB, Gilchrist J, Pickwell LD, Sheridan M, Weatherill J, Whitaker D. The subjective assessment of cataract. Ophthalmic Physiol Opt 1989;9:16-19.

24. Pardhan S, Gilchrist J. The importance of measuring binocular contrast sensitivity in unilateral cataract. Eye 1991;5: 31-5.

25. Abrahamson M, Sjostrand J. Impairment of contrast sensitivity function as a measure of disability glare. Invest Ophthalmol Vis Sci 1986;27:1131-6.

26. Tupper B, Miller D, Miller R. The effect of a $55 \mathrm{~nm}$ cut-off filter on the vision of cataract patients. Ann Ophthalmol 1985;17:67-72.

27. Ijspeert JK, deWard PWT, van den Berg TJTP, deJong PTVM. The intraocular straylight function in 129 healthy volunteers; dependence on angle, age and pigmentation. Vision Res 1990;30:699-707.

28. Boettner EA, Wolter JR. Transmission of the ocular media. Invest Ophthalmol 1962;1:776.

29. Lerman S, Borkman RF. Spectroscopic evaluation and classification of the normal aging and cataractous lens. Ophthalmic Res 1976;8:335-53.

30. Smith GTH, Smith RC, Brown NAP, Bron AJ, Harris ML. Changes in light scatter and width measurements from the human lens cortex with age. Eye 1992;6:55-9.

31. Mellerio J. Yellowing of the human lens: nuclear and cortical contributions. Vision Res 1987;27:1581-7.

32. Lyne AJ, Phillips CI. Visual field defects due to opacities in the optical media. Br J Ophthalmol 1969;53:119-22.

33. Guthauser U, Flammer J. Quantifying visual field damage caused by cataract. Am J Ophthalmol 1988;106:480-4.

34. Heider HW, Sees KJ, Schnaudigel OE. Cataract induced visual field changes. Klin Monatsbl Augenheilkd 1991;198: 15-19.

35. Ferris FL, Kassof A, Bresnick GH, Bailey I. New visual acuity charts for clinical research. Am J Ophthalmol 1982; 94:91-6.

36. Elliott DB, Sheridan M. The use of accurate visual acuity measurements in clinical anti-cataract formulation trials. Ophthalmic Physiol Opt 1988;8:397-401.

37. Holladay JJ, Prager TC, Trujillo J, Ruiz RS. Brightness acuity test and outdoor visual acuity in cataract patients. J Cataract Refract Surg 1987;13:67-9.

38. Hess R, Woo G. Vision through cataracts. Invest Ophthalmol Vis Sci 1978; 17:428-35. 